\title{
Evidence for limited adaptive responsiveness to large-scale spatial variation of habitat quality
}

\author{
Karl-Michael Werner ${ }^{1, *}$, Marc H. Taylor ${ }^{1}$, Rabea Diekmann ${ }^{2}$, Josep Lloret ${ }^{3}$, \\ Christian Möllmann ${ }^{4}$, Raul Primicerio ${ }^{5}$, Heino O. Fock ${ }^{1}$ \\ ${ }^{1}$ Thünen Institute of Sea Fisheries, Herwigstraße 31, 27572 Bremerhaven, Germany \\ ${ }^{2}$ Thünen Institute of Fisheries Ecology, Herwigstraße 31, 27572 Bremerhaven, Germany \\ ${ }^{3}$ University of Girona, Faculty of Sciences, 17003 Girona, Spain \\ ${ }^{4}$ Institute for Marine Ecosystem and Fisheries Science, Center for Earth System Research and Sustainability (CEN), \\ University of Hamburg, Grosse Elbstrasse 133, 22767 Hamburg, Germany \\ ${ }^{5}$ The Arctic University of Norway, 9037 Tromsø, Norway
}

\begin{abstract}
The ability of organisms to adapt their foraging behaviour to spatial variations in food availability and habitat quality is crucial to maximize energy intake and hence fitness. Under ideal conditions, habitat selection should result in a spatial distribution of individuals such that their fitness (energy reserves or condition) is roughly equal across habitats of varying quality. Using $11 \mathrm{yr}$ of field data on Atlantic cod Gadus morhua distribution along the Greenland shelf, we investigated the foraging behaviour and life history of cod in heterogeneous environments. We combined information on energy reserves of cod with spatially resolved diet composition data to derive a measure of habitat quality and heterogeneity. Energy reserves in individual fish were best explained by the particular area they inhabited, whereas growth, population density, food quantity and interannual effects were of minor importance. Condition differed on relatively small spatial scales, at which cod would be capable of redistributing in favour of high-quality habitats. Our results indicate that particular areas may persistently allow higher fitness by sustaining highconditioned individuals but suggest that replenishment of well-conditioned individuals in these high-quality habitats may take longer than expected. We conclude that cod exhibited limited scope in its behavioural response to spatial variation of habitat quality, leading to persistent spatiotemporal differences in energy reserves. Current climate change and fishing activities alter ecosystems and affect habitat heterogeneity, and the adaptive responsiveness of species to such changes in habitat quality is important in natural resource management.
\end{abstract}

KEY WORDS: Atlantic cod $\cdot$ Habitat choice $\cdot$ Behaviour $\cdot$ Fitness $\cdot$ Diet

\section{INTRODUCTION}

Habitat selection is an important aspect of foraging behaviour influencing many life-history traits, such as growth and maturation schedules as well as fecundity (Sutherland 1996, Stamps 2009, Morris 2011). Use of poor-quality habitats leads to reduced condition and fitness due to low food intake, whereas surplus energy storages obtained in high-quality habitats can enhance reproductive potential (Sutherland 1996,

\footnotetext{
${ }^{*}$ Corresponding author: karl-michael.werner@thuenen.de
}

Lloret et al. 2013, Mcbride et al. 2015). The amount of energy that individuals can acquire in a habitat mainly depends on resource richness, number of consumers and their competitive abilities (Sutherland 1996, Munday 2001, Morris 2011). Ultimately energy intake reflects an individual's ability to respond to environmental heterogeneity in space and time (Sutherland 1996, Munday 2001, Casini et al. 2016b).

A successful model of habitat choice predicting consumer distribution in relation to resource availability

(C) The authors 2019. Open Access under Creative Commons by Attribution Licence. Use, distribution and reproduction are unrestricted. Authors and original publication must be credited. 
is called 'ideal free distribution' (IFD) (Fretwell \& Lucas 1969, Sutherland 1996, Stamps 2009). IFD is a conceptual model, which predicts that all individuals in particular areas and populations should have approximately the same realized fitness because they distribute themselves according to the available food resources (Fretwell \& Lucas 1969, Kacelnik et al. 1992, Sutherland 1996). The model assumes that all individuals are equal in their competitive abilities, can freely move in the environment, have perfect knowledge of resource distribution, always choose the best habitat and that traveling between habitats has no costs (Fretwell \& Lucas 1969, Kennedy \& Gray 1993, Sutherland 1996). As a result, individuals should move to areas with the highest resource availability first, until increasing density causes a reduction of fitness, whereby individuals start to utilize less-suitable habitats (Fretwell \& Lucas 1969, Kacelnik et al. 1992, Sutherland 1996). However, the assumptions of ideal behaviour and equal competitive abilities are simplifications, and while studies conducted on smaller scales, such as tank experiments or field studies from freshwater lakes, often show similar fitness across food patches, distribution patterns on large scales often show discrepancies compared to IFD predictions (Tregenza 1995, Sutherland 1996, Stamps 2009). Reasons for these discrepancies are mainly imperfect knowledge of resource distribution, interference, unequal competitive abilities and varying travel cost, all of which violate the assumptions behind IFD (Abrahams 1986, Kennedy \& Gray 1993, Tregenza 1995). Especially on larger scales, animals are often not capable of correctly perceiving the true distribution of resources, because searching behaviour and extensive screening of the environment is too costly and may increase the risk of mortality (Sutherland 1996, Stamps 2009). This often implies that individuals would rather accept lower-quality habitats, and the resulting relative density in each particular habitat or food patch does not correctly reflect its intrinsic resource quality (Stamps 2009). It appears that the optimization processes necessary to obtain equal fitness in a heterogeneous environment require high degrees of behavioural plasticity and responsiveness. Considering the rapidity and magnitude of expected environmental changes under global warming, it is important to investigate whether animals can quickly respond to spatial variation of habitat quality (Sutherland 1996, Morris 2011, Fossheim et al. 2015).

We investigated the large-scale habitat selection, adaptive behaviour and the influence of habitat quality on food intake and energy acquisition of Atlantic cod Gadus morhua, a widely distributed marine pre- dator and an ecologically and economically iconic species (Kurlansky 2011). Cod is an ideal study species for this purpose because it is considered to be an opportunistic feeder, wherein stomach contents reflect the species composition in the environment and individuals can be used as environmental samplers (Lilly \& Parsons 1991, Fahrig et al. 1993, Link \& Garrison 2002). The study was carried out on the populations located on the subarctic Greenland shelf (Fig. 1a), which is one of the northernmost areas of cod distribution. The environment is considered quite heterogeneous, resulting in a relatively patchy distribution of mature cod among the banks of the area. Here, the cod populations respond rapidly and extensively to environmental fluctuations, and climate change will likely alter ecosystem structure and habitats (Rätz \& Lloret 2003, Drinkwater 2005, Fossheim et al. 2015). Throughout the study area, energy reserves (i.e. liver condition) and growth of cod vary spatially, indicating that the populations might not be ideally distributed and that fitness might vary among areas (Fig. 1; for methodology, see Section 2). We used cod diet to draw direct conclusions about the surrounding habitat structure (Lilly \& Parsons 1991, Fahrig et al. 1993, Link \& Garrison 2002).

In this study, we used $8 \mathrm{yr}$ of data collected over $11 \mathrm{yr}$, allowing for the investigation of spatio-temporal patterns of energy reserves and their relationship with food quality, fish density and growth. By combining spatially resolved data of food composition and energy reserves, which was used to infer habitat quality and resource distribution, we investigated whether energy reserves and distribution patterns respond to environmental conditions.

\section{MATERIALS AND METHODS}

\subsection{Data collection and sampling strategy}

We based all analyses on samples collected during 8 groundfish surveys with FRV 'Walther Herwig III' in Greenland waters during the periods of 2006-2011 and 2015-2016 (Fig. 1a). Each year, the survey started east off Greenland in mid-October from where sampling was carried out in offshore areas southwards towards the southern tip and northwards to West Greenland during an approximate total sampling duration of $4 \mathrm{wk}$. Samples were collected using a fisheries survey bottom trawl net. The survey area was pre-stratified into 7 subareas with a maximum depth of $400 \mathrm{~m}$ (Fig. 1a), of which each subarea was subdivided into a shallow $(<200 \mathrm{~m})$ and a deep (200- 
a) Study area

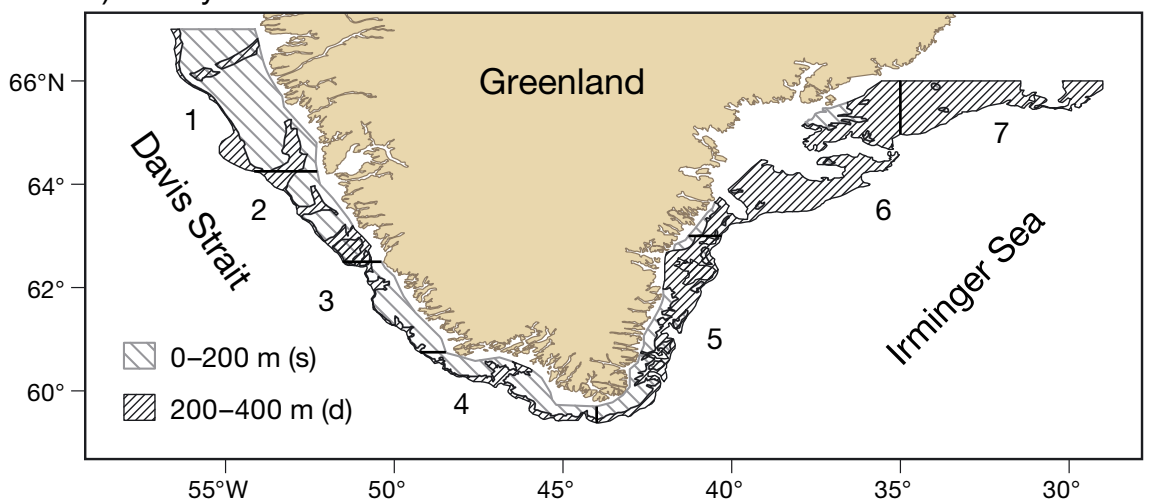

c) Length $(\mathrm{cm})$

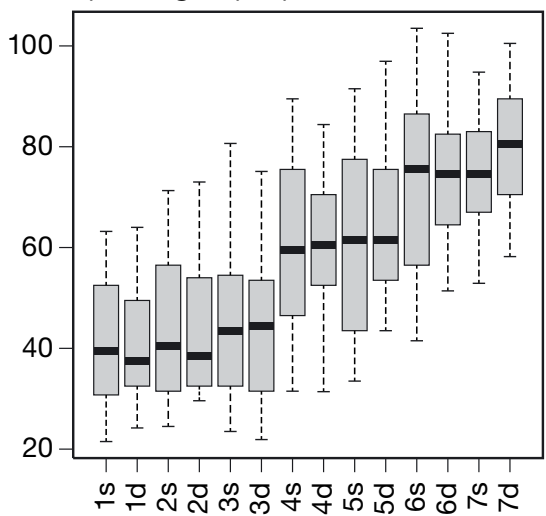

d) Density (no per station)

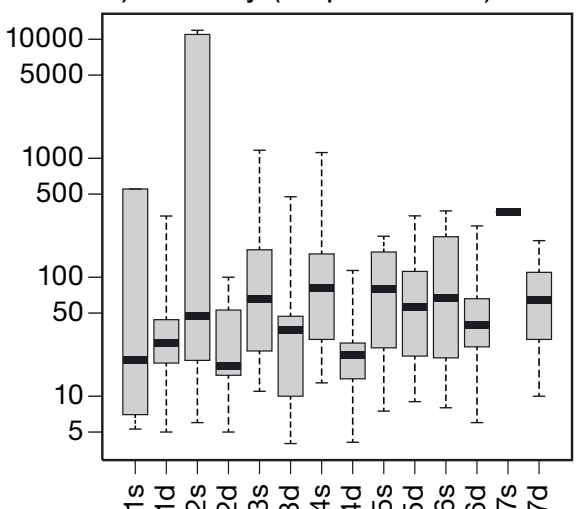

b) Energy reserves

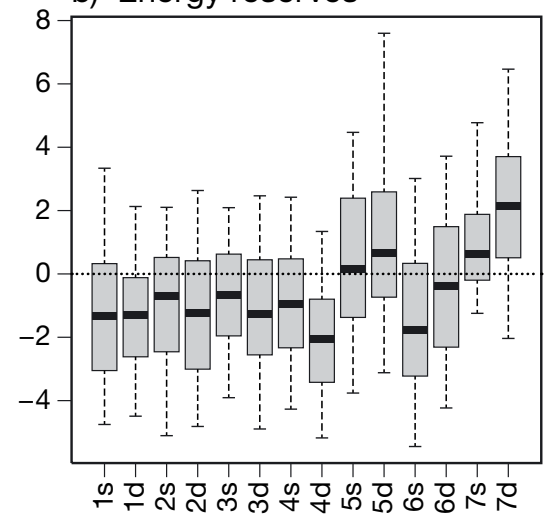

e) Growth

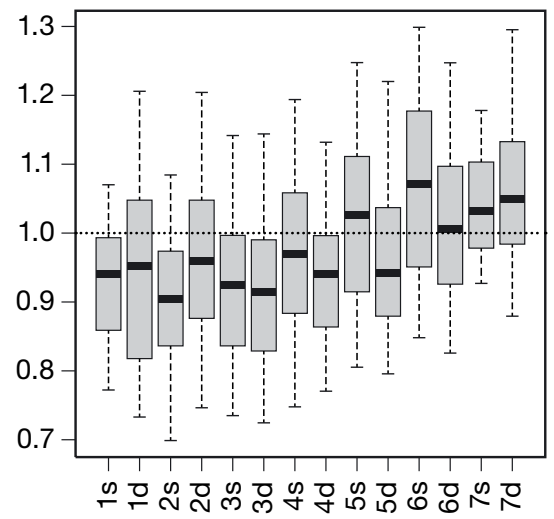

Fig. 1. (a) Study area as divided into 7 subareas (1-7). Each subarea was further subdivided into a shallow (s; 0-200 m) and a deep ( $d_{;}$200-400) zone. (b) Spatial variation of energy reserves, (c) length distribution over the 14 different subareas, (d) spatial variation of cod density, (e) spatial variation of growth (residual length at age). For all box-whisker plots, box limits are the $25 \%$ and $75 \%$ quantiles, with the median denoted by the bold line. Whiskers show the $90 \%$ quantiles $(5 \%$ and $95 \%$ )

$400 \mathrm{~m}$ ) part. At least five $30 \mathrm{~min}$ hauls in each of the 14 subareas at fixed locations were planned for each survey. Because poor weather conditions often restricted sampling effort in November, sample coverage was generally better in East and South Greenland (Subareas 4 to 7) than in West Greenland (Subareas 1 to 3) (see Table S1 in the Supplement at www.int-res.com/articles/suppl/m629p179_supp. pdf). If catches allowed, at least 30 cod were sampled to obtain a representative length distribution of the total catch. When catches were $>30$ fish, 30 fish were randomly sampled to cover the complete size range of the catch including minimum and maximum lengths and not more than 5 individuals per $1 \mathrm{~cm}$ size class. Total length was measured to the nearest $1 \mathrm{~cm}$ and eviscerated weight and liver weight to the nearest 1 decigram. Only fish whose stomachs were not everted were used for the study. Stomachs were removed from the abdominal cavity and individually frozen at $-30^{\circ} \mathrm{C}$ for later analysis. Age was deter- mined by reading annual rings in the ear stones (i.e. otoliths) and used to compute the mean length at age for each age class. When weather and time restrictions allowed, in situ bottom temperature data were collected using a CTD.

\subsection{Diet composition and habitat heterogeneity}

To gain insight into the spatial habitat heterogeneity of the area inhabited by cod Gadus morhua along the Greenland shelf, diet composition was determined by analysing stomach contents, which were assumed to roughly represent the prey composition in the environment (Lilly \& Parsons 1991, Fahrig et al. 1993, Link \& Garrison 2002). Stomach contents are assumed to represent recent local feeding activity based on estimated evacuation rates and home ranges for cod. In particular, $50 \%$ of the stomach contents are usually evacuated within $24 \mathrm{~h}$ (dos Santos \& 
Jobling 1991), and home ranges of cod are considered to be relatively small, on average $<10$ ha for juveniles and sub-adults in coastal Newfoundland (Bradbury et al. 2008). Even over time periods of $>2 \mathrm{yr}$, tagged cod $(38-81 \mathrm{~cm})$ were observed to have home ranges $<15 \mathrm{~km}$ (Neat et al. 2006). Diet composition is one of the strongest predictors of energy storage levels in cod and influences vitality, fertility, egg quality and mortality (Kjesbu et al. 1991, Morais et al. 2001, Mcbride et al. 2015). Identification of fish species in the stomachs was conducted either visually or by examining the species-specific shape of the ear stone, which was compared with the available literature (Whitfield \& Blaber 1978, Whitehead et al. 1984, Härkönen 1986, Scott \& Scott 1988, Campana 2004) and a reference collection available at the Thünen Institute of Sea Fisheries. Wet weight of each prey item was measured to the nearest $1 \mathrm{mg}$. Statistical analyses and the comparison of feeding habits required the grouping of some taxa into taxonomically or functionally distinct categories. Rarely occurring species or groups were grouped based on their position in the water column, i.e. pelagic or benthic. If this could not be distinguished (mainly for decapoda and cephalopoda), taxa were assigned to one of the 3 groups 'crustacea others', 'fish others' or 'others'. Due to its relative importance and ease in identification, capelin Mallotus villosus represented a separate taxonomic category. Diet items were identified as 'benthic remains', when they could not be clearly identified but related to benthic feeding (i.e. stones or sponges). Altogether, 14 prey categories were used in the statistical analyses (Table S2). In some cases, the degree of digestion prevented identification, and stomachs which contained $>70 \%$ of unidentified prey material were excluded from the analysis. All other samples deemed acceptable for the analysis $(\mathrm{N}=3315)$ were standardised through conversion to proportional data (sum equal to 1.0). To indicate if diet quantity was important to predict energy reserves, we calculated the total fullness index (TFI) for each individual (Daan 1973, Lilly \& Parsons 1991), relating stomach content weight to fish length, using:

TFI $=$ (full stomach weight - empty stomach weight)

$$
\text { fish length }{ }^{3} \times 1000
$$

\subsection{Energy reserves and growth performance}

To indicate individual growth performance and long-term feeding success, we calculated a growth index by dividing each individual's length at age of capture by the mean length at age for the corresponding age class:

$$
\text { Growth index }=\frac{\text { individual length at age }}{\text { mean length of that age group }}
$$

In cod, the amount of energy acquired is reflected in the liver size because cod store energy in the liver, which increases in weight during the feeding season and from where energy is transferred to the gonads prior to reproduction (Bogucki \& Trzesinski 1950, Røjbek et al. 2012, Lloret et al. 2013). Large energy storages indicate high-quality food supply and a lipid-rich diet, which is advantageous during reproduction and leads to increased fecundity of cod (Lie et al. 1988, Marteinsdottir \& Steinarsson 1998, Marshall et al. 1999). However, while energy reserves as represented in the liver index provide one of the most important parental effects on fitness (Kjesbu et al. 1991, Lambert \& Dutil 1997, Marshall et al. 1999), using this index has limitations because it cannot capture all factors driving the reproductive success of an individual. The liver index reacts to changing diets within 8 to $12 \mathrm{wk}$, which makes it a seasonally and spatially dynamic index, but it cannot reflect long-term patterns and might have spatially differed because of fish movements several months before our field sampling (Lie et al. 1988, Morais et al. 2001, Pardoe et al. 2008). Fatty acid composition in the gonads can vary with differing diets and influence reproductive success but remain undetected through liver size (Røjbek et al. 2012, Stoltenberg 2019).

The liver index was used as proxy for the size of energy reserves and calculated using:

$$
\text { Liver index }=\frac{\text { liver weight }}{\text { eviscerated weight } \times 100}
$$

Because the mean and the variance of liver index increased with fish length and hence varying liver indices could be an artefact of fish lengths, we fitted a generalized additive model with $\log \operatorname{link}(\mathrm{p}<$ $0.001)$ :

$$
L_{i}=\exp \left[\beta_{0 i}+s\left(T_{i}\right)+\beta_{1 i} A_{i}\right]+\varepsilon_{i}
$$

where liver index $L$ is the dependent variable, the independent variable $T$ is total fish length, $A$ is the year for each sample $i, s$ is a penalized spline, and $\varepsilon$ is the gamma-distributed error. Year was used as a factor to consider interannual differences, e.g. due to fluctuations in population size or feeding conditions. Model residuals were subsequently used to visualize the spatial variation of energy reserves (Fig. 1b). 


\subsection{Statistical analysis}

To test the validity of ideal free distribution and relate energy reserves to fish density, individual growth and temporal and spatial patterns of diet, we divided our statistical approach into a univariate and a multivariate part. All statistical analyses were conducted using R software v.3.5.1 (R Development Core Team 2016) using the packages vegan (Oksanen et al. 2018), MuMIn (Bartoń 2012) and mgcv (Wood 2011). Figures were created using ggplot 2 (Wickham 2016).

To test if individuals have the same condition across different areas, univariate multiple regression models were used to explore variables influencing the liver index. A generalized linear model with s log link and a gamma-distributed error term was used with liver index as the response and fish length, subarea, year, density (number of cod per station), total fullness index and growth as explanatory variables. Subarea and year were used as factors, and additionally 2-way interactions were tested between length and subarea respectively by year as well as between year and subarea. All possible term combinations were fit using the 'dredge' function of the MuMln package (Bartoń 2012). Marginality constraints were respected such that a given interaction term was included with their respective main effects and all lower-order terms. The potential role of bottom temperature was investigated in a separate model because temperature data were only available for 2850 of 3315 samples. The most parsimonious model was selected (Crawley 2005) using the Bayesian information criterion (BIC) (Schwarz 1978). BIC was chosen over Akaike's information criterion (AIC) (Akaike 1974) because BIC adapts better to the number of samples and punishes complex models based on high sample sizes (3315 in our study) (Aho et al. 2014). The most parsimonious model (without temperature) was:

$$
L_{i}=\exp \left(\beta_{0 i}+\beta_{1 i} \times T_{i}+\beta_{2 i} S_{i}\right)+\varepsilon_{i}
$$

where $L$ is the dependent variable liver index, $T$ is the total fish length, and $S$ is the subarea for each sample $i$. The error term $\varepsilon$ was assumed to be gamma-distributed.

Patterns in diet composition were explored using canonical correspondence analysis (CCA), a multivariate approach, which uses gradients in an independent set of explanatory variables to explain variability in a multivariate response data matrix (Greenacre \& Primicerio 2013). The response matrix was the individual diet composition according to the 14 main prey categories. Explanatory variables included fish length (numeric), energy reserves (numeric), subarea (factor) and year (factor). In accordance with the above-described generalized linear model, the model included all single-effect terms, all 2-way interaction terms between fish length, energy reserves and subarea, and an additional 2-way interaction between subarea and year in order to account for potential inter-annual spatial differences of environmental conditions. The significance of the variables was tested with PERMANOVA (Anderson 2001). In addition to the CCA model itself, we used the model's results to predict diet composition based on the explanatory variables and to visualize trends in dietary changes as related to fish length and energy reserves. Results from the CCA model are presented as pseudo$F$ values, the ratio of constrained and unconstrained total inertia, which indicates the explained variance by each explanatory term. Predicted diet compositions were aggregated according to 5 length class $(20-40,40-60,60-80,80-100$ and $>100 \mathrm{~cm})$ and 4 liver index class $(0-4,4-8,8-12$ and $>12)$ combinations. These aggregated values were rescaled to be within a positive range of 0 to 1 , followed by conversion into percentage contribution for visualization in stacked bar plots. A biplot of the 2 leading CCA dimensions further demonstrated the relationship between feeding strategies and the 4 explanatory variables fish length, energy reserves, subarea and year.

\section{RESULTS}

\subsection{Comparing cod Gadus morhua distribution to ideal free distribution}

The model revealed a strong spatial gradient of energy reserves with increasing values from west to east (Fig. 1b). The most parsimonious model explaining energy storages included subarea and fish length as single terms (lowest BIC) (Table 1), providing evidence against an ideal and free distribution. Subarea $(F=151.4)$ had greater explanatory power than fish length $(F=86.4)$, although both were highly significant $(p<0.001)$ (Fig. 1a,b, Table S3 in the Supplement). Deep stations in Subarea 7, an area in East Greenland bordering on the northern slope of the Irminger Sea, showed highest energy storages for 3 out of 5 length classes (Fig. S1). Year and stomach fullness were included in the second-best model. In the alternative model considering bottom temperature as an additional explanatory variable, the most 
Table 1. Generalized linear models testing the effects of year, fish length, density and subarea on energy reserves (liver index) of Greenland cod. Ranked from lowest to highest Bayesian information criterion (BIC). Term inclusion in a given model is indicated by a plus symbol $(+)$. The interactions Year:Fish length, Year:Subarea, Fish length:Density and Subarea:Density were not included in the top 10 models

\begin{tabular}{|c|c|c|c|c|c|c|c|c|c|}
\hline Rank & Year & $\begin{array}{l}\text { Fish } \\
\text { length }\end{array}$ & Density & Subarea & $\begin{array}{l}\text { Stomach } \\
\text { fullness }\end{array}$ & Growth & $\begin{array}{l}\text { Length: } \\
\text { Subarea }\end{array}$ & $\mathrm{df}$ & $\mathrm{BIC}$ \\
\hline 1 & & + & & + & & & & 16 & 15456 \\
\hline 2 & + & + & & + & + & & + & 37 & 15456 \\
\hline 3 & + & + & & + & + & & & 24 & 15457 \\
\hline 4 & & + & & + & & & + & 29 & 15458 \\
\hline 5 & + & + & & + & & & + & 36 & 15458 \\
\hline 6 & & + & & + & + & & & 17 & 15459 \\
\hline 7 & + & + & & + & & & & 23 & 15460 \\
\hline 8 & + & + & + & + & + & & + & 38 & 15461 \\
\hline 9 & & + & & + & + & & + & 30 & 15462 \\
\hline 10 & & + & & + & & + & & 17 & 15462 \\
\hline
\end{tabular}

(Table S5). Fish above $60 \mathrm{~cm}$ with high liver weights and large amounts of energy stored were associated with a diet of mesopelagic fish, hyperiids (pelagic amphipods) and other crustaceans, which were found in the deep areas off north-eastern Greenland (deep Subarea 7) (Fig. 3). Low energy reserve (i.e. negative CCA1 coordinates; Fig. 3) values were associated with increasing proportions of benthic remains, gammarids (benthic amphipods), euphausiids, gadoids and related to shallow parts of Subareas 3, 4, 5 and 6. Piscivory independent of the main prey species was related to larger energy values for the 2 smallest length groups, 20-40 and 40-60 $\mathrm{cm}$, with especially

parsimonious model included subarea, fish length, bottom temperature and year, indicating stronger interannual effects and an influence of temperature on energy reserves, with higher energy reserves being negatively associated with lower water temperatures (Table S4). The growth index combined for all age classes showed an increasing trend from west to east, indicating that faster-growing fish were more easterly distributed. Although the west-east gradient was prevalent for both energy reserves and growth, these factors strongly differed on smaller scales (Fig. 1b,e). For example, individuals in Subareas 6 and 7 showed similar individual long-term growth but differed strikingly in terms of energy reserves (Fig. 1b,e). Energy reserves were generally larger in deeper than in shallower subareas, whereas fastergrowing fish tended to be distributed in shallower areas, especially in Subareas 4, 5 and 6 (Figs. 1b \& 3).

\subsection{Habitat heterogeneity, diet quality and their influence on energy reserves}

Energy reserves in different subareas showed distinct relationships to particular diet compositions, which we used to infer habitat heterogeneity (Figs. 24). CCA was used to explore the influence of several biotic and abiotic factors on diet composition. The prediction revealed that at a given size, fish diet composition is related to energy reserves. All predictors except for the interaction term of length and energy reserves were highly significant (Table S5). Single terms were most significant, as revealed by pseudo- $F$ values, with fish length and energy reserves being of greatest significance in explaining diet composition capelin showing a positive correlation (Fig. 4). At all length groups, the proportion of euphausiids, gammarids and benthic remains in the diet were particularly high when energy reserves were low (Figs. 3 \& 4). Cod longer than $80 \mathrm{~cm}$ showed stronger piscivorous feeding behavior, and the proportion of euphausiids in the diet decreased accordingly (Fig. 4). Consumption of gadoids, which includes cannibalism, was related to lower average energy values in all but the smallest length group (Fig. 4). Overall, euphausiids, especially Meganyctiphanes norvegica, were the most abundant food item over all samples, being the dominant prey in one-third of all stomachs across all length classes (Fig. 1, Table S2).

\section{DISCUSSION}

We showed that significant spatial differences in energy reserves in cod Gadus morhua populations from the Greenland shelf were likely caused by variable food quality as a result of pronounced habitat heterogeneity. Growth indices, which we assume to be related to competitive abilities, did not predict the amount of energy stored. Even on smaller scales of $<100 \mathrm{~km}$ difference between sites, where cod appears to be physiologically able to switch between food patches, energy reserves differed between habitats. We conclude that cod individuals often remained in suboptimal habitats, leading to persistent spatio-temporal patterns of fish with different amounts of energy reserves. These observations are not consistent with an ideal free distribution (IFD), not even at the smaller spatial scales for which the IFD model is more readily applicable. 


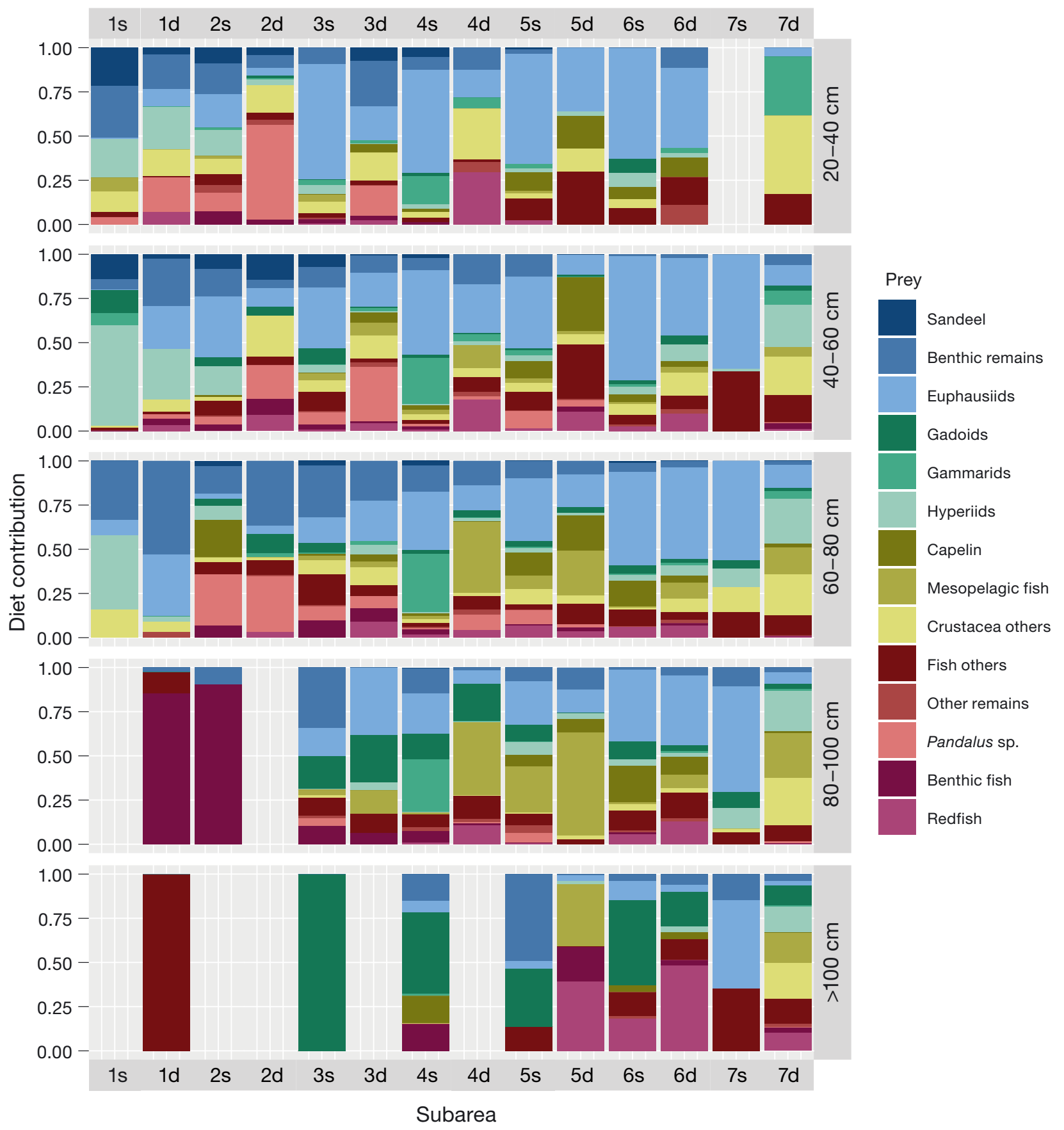

Fig. 2. Spatial and size-dependent variation of Atlantic cod diet composition off Greenland. Letters 's' and 'd' indicate shallow $(0-200 \mathrm{~m})$ and deep $(200-400 \mathrm{~m})$ zones, respectively, of the given subarea

\subsection{Different diet compositions cause fluctuations in energy reserves}

Spatial differences in the observed energy reserves were likely influenced by food quality, indicated by diet composition. Mesopelagic fish are often very rich in lipids (Falk-Petersen et al. 1986, Lea et al.
2002, Spitz et al. 2010), which probably had a positive influence on energy levels in Subareas 5 and 7 because these areas are rich in this type of fish. Our results showed that here cod had access to food from the mesopelagic realm from the deep scattering layer in the Irminger Sea. The largest energy reserves might be partially explained by bottom trapping 


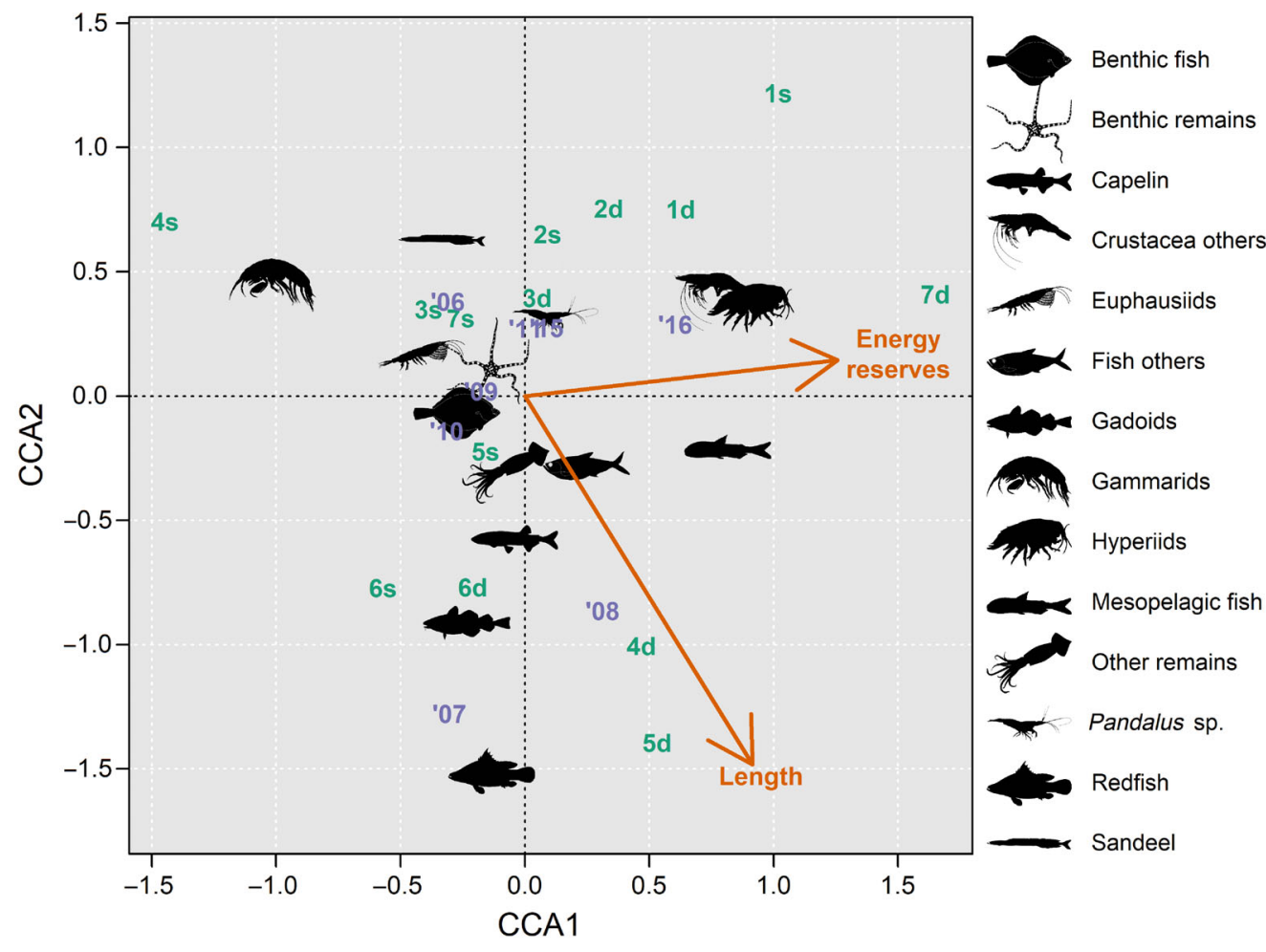

Fig. 3. Ordination diagram based on canonical correspondence analysis showing ordination axes 1 (CCA1) and 2 (CCA2), relating cod feeding patterns to energy reserves, length, subarea and year. All explanatory variables were used as single predictors for diet composition. Diet item biplot scores are shown by the silhouette symbols. Arrows indicate biplot scores of continuous explanatory variables, while scores of factor variables year (blue) and subarea (green) are indicated by text. Letters ' $\mathrm{s}$ ' and ' $\mathrm{d}$ ' indicate shallow (0-200 m) and deep (200-400 m) zones, respectively, of the given subarea. Silhouette image credits, see 'Acknowledgements' mechanisms, whereby vertically migrating organisms are trapped above physical obstacles, such as seamounts or slopes, which prevent migration to greater depths (Genin \& Dower 2007). We speculate that this mechanism results in the retention of highquality food that is easily accessible for feeding. This advantage might have contributed to the differences in energy reserves between deep Subarea 7 and Subareas 4 and 5, where considerable amounts of mesopelagic fish were also found in the diet. Benthic feeding on, e.g., brittle stars, polychaetes, sea cucumbers or gammarids, typically for cod inhabiting shallower banks, resulted in lower energy gains, which is likely driven by the low levels of organic matters and caloric content in many benthic invertebrates (Tyler 1973, Atkinson \& Wacasey 1976, Norrbin \& Båmstedt 1984). It must be further considered that Meganyctiphanes norvegica, which is generally a lipid-rich organism, has its annual peak in lipid content in January and its minimum in July (FalkPetersen et al. 2000), which means that cod caught during the autumn season covered by the surveys were feeding on krill with comparatively low lipid content. However, general assumptions about lipid contents and energy levels of food organisms could not be made because caloric content of different zooplankton and fish species can vary between regions, seasons, habitats, sexes and maturity stages
(Henderson et al. 1984, Falk-Petersen et al. 1986, Lee et al. 2006).

\subsection{Causes of large-scale deviations from ideal habitat selection theory}

IFD as a conceptual ecological model and framework to predict consumer distributions related to resource availability has been tested for a variety of areas, scales and taxa (Kennedy \& Gray 1993, Sutherland 1996, Morris 2011). Because it is not unusual that observations in ecology contradict the IFD model assumptions, our results of large-scale unequal patterns of energy reserves are not surprising, considering the spatial extent and heterogeneous environments of our study area (Stamps 2009). It appears that a lack of knowledge of the spatial distribution of resources combined with limited capacities to risk potentially fitness-costly searching behaviour likely cause large-scale deviations from an ideal and free habitat selection. Because large, mature cod display a patchy distribution on underwater banks in East Greenland, we hypothesize that traveling between these banks through 'food valleys', i.e. areas of low food availability and quality, would be energetically costly and impose substantial risks of starvation, which probably precludes extensive screening of the 


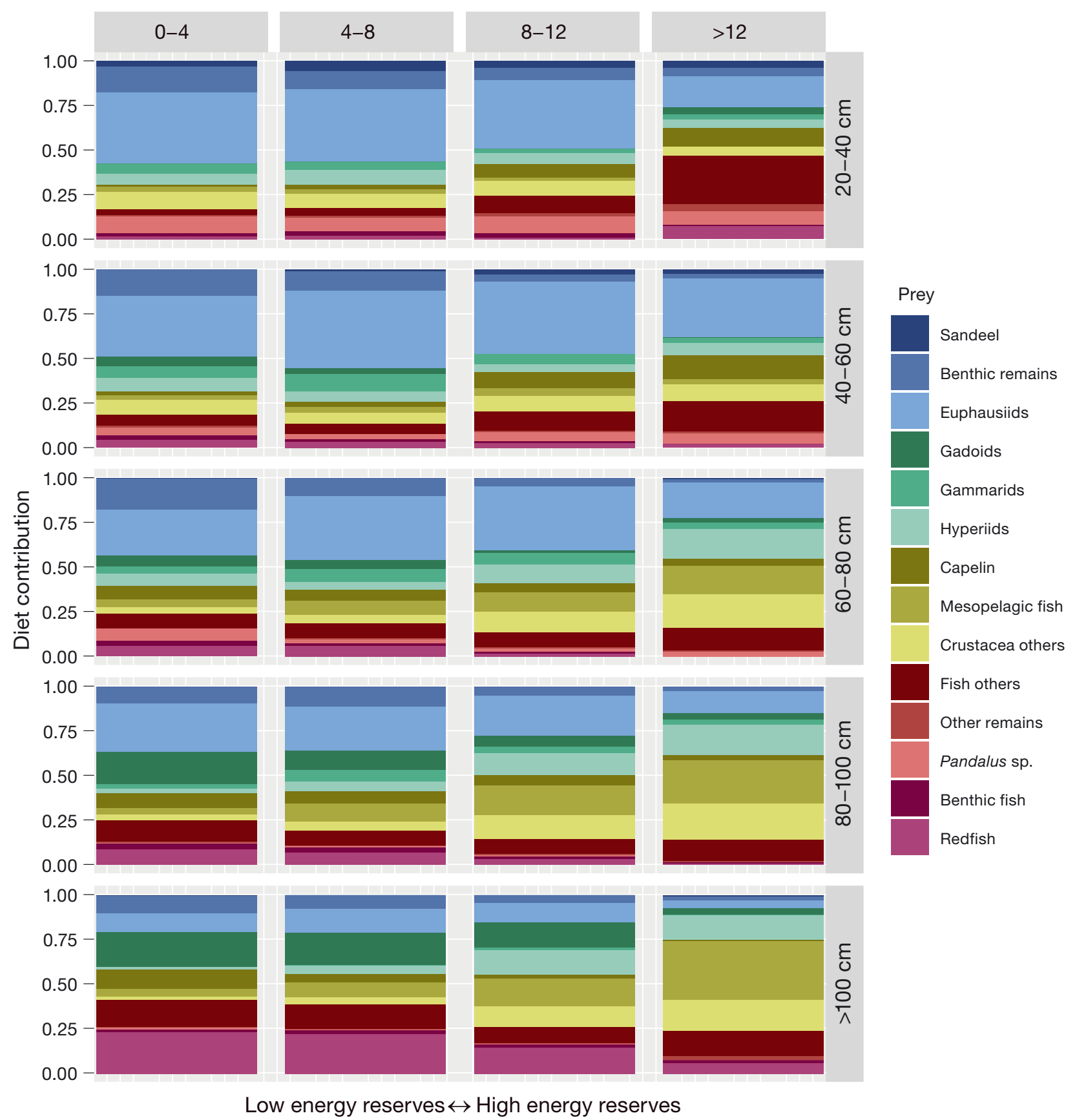

Fig. 4. The influence of fish length and energy reserves on diet composition of Atlantic cod off Greenland predicted by canonical correspondence analysis for different length $(20-40,40-60,60-80,80-100$ and $>100 \mathrm{~cm})$ and energy reserves (liver index) $(0-4,4-8,8-12$ and $>12)$ categories

environment. Fish from areas with poor habitat quality, such as southern Greenland, might exhibit increasingly restricted explorative behaviour because of low energy reserves, which can amplify poor condition because weak fish have a lower probability of discovering high-quality habitats (Stamps 2009). It seems that active habitat selection in the sense of choosing the ideal environment to maximize fitness based on perfect knowledge of the environment did not take place, because cod individuals did not extensively screen the environment for food availability. The observed length-stratification of cod around Greenland shows that the main areas of distribution of juvenile and adult fish do not overlap because of 
the migration of maturing individuals with increasing age (Hovgård \& Wieland 2008). The timing of the migration from west to east Greenland seems to be related to higher growth rates, because mean length at age was higher in east Greenland. These results indicate that individuals start to migrate eastwards as soon as they reach a certain size, independent of age, because faster-growing fish tend to be more easterly distributed than conspecifics of the same age but with slower growth. Especially in West Greenland, individuals from inshore and fjord areas are more sedentary than from coastal and offshore areas, resulting in spatial differences of migratory behaviour and stationarity (Storr-Paulsen et al. 2004). However, our samples were all taken in offshore areas, and we assume that differences in stationarity do not play a major role. It remains speculative as to why particular individuals migrate to and occupy highquality habitats, such as deep banks in Subarea 7, and others to low-quality habitats, such as shallow areas in subarea 6 , which are seperated by a distance adult cod would be physiologically capable of overcoming. A possible explanation is that these distribution patterns were caused by natal homing, which is a common behaviour and driver of migration patterns in cod, where individuals migrate to areas for reproduction that correspond to their own natal spawning grounds (Svedäng et al. 2007, Bonanomi et al. 2016). Once an individual has ended up in that particular spawning area, it might be not only the lack of behavioural plasticity leading to the acceptance of lowquality habitats but simply the impossibility to behave ideally because of increasing risks of death. It seems that once an individual finds a suitable habitat for surviving and reproducing, even if fitness is not maximized, it accepts imperfect conditions rather than risking costly travel to potentially better habitats. Although the alternative model (see Table S4 in the Supplement) indicated that bottom temperature is correlated with energy reserves, we assume that this is an indirect relationship. Bottom temperatures were lowest in deep Subarea 7, where cod with higher energy reserves were found. Similar to the results from our study, cod individuals with good condition are frequently found in deeper waters around Iceland (Pardoe et al. 2008). However, lower temperatures may be linked to better cod condition through trophic effects: In Iceland, greater energy reserves in deep areas were associated with high abundance of capelin (Pardoe et al. 2008). Similarly, in the Barents Sea, food availability had a stronger effect on cod condition than temperature (Yaragina \& Marshall 2000). These results are supported by experimental studies, where energy reserves (liver condition) of cod were not significantly related to different temperature regimes (Yoneda \& Wright 2005a,b), while food quality and quantity are known to directly influence liver condition (Lie et al. 1988, Morais et al. 2001, Yoneda \& Wright 2005a). Although the results of our study and previous ones conducted in Greenland waters (Lloret \& Rätz 2000, Rätz \& Lloret 2003) indicate that condition and productivity of cod stocks are linked to water temperatures, we suggest that the effect of water temperature on the energy reserves of cod is an indirect (trophic) effect that needs to be further investigated.

\subsection{Implications for ecosystem-based management}

Although our observed violations of ideal habitat selection were not unexpected, we identified $2 \mathrm{im}$ portant aspects that may have far-reaching implications for eco-evolutionary processes and natural resource management. First, the observed spatial differences in energy reserves were temporally stable over our study period, and second, spatial differences were only influenced to a minor degree by density, food quantity or growth. Hence, density-dependence and individual competitive abilities seemed to be of minor importance in restricting energy gain. Greenland cod did not show increased density in high-quality habitats, which would have been the expected behavioural response to spatial variations in resource quality. These results confirm that important life-history traits, such as growth, reproduction, condition and survival, may depend on habitat type and quality and the ability to adapt to heterogeneous environments. They furthermore add to the eco-evolutionary perspective that missing capabilities to balance these spatial differences may lead to persistent differences in fitness between individuals, which have occupied and fed in different environments. Hence, our results indicate that the observed patterns are not an evolutionarily stable strategy (ESS), where all competitors would have been found in the environment with the highest resource rewards (Smith \& Slatkin 1973, Parker \& Sutherland 1986, Cressman \& Křivan 2010). Because condition affects reproduction, growth and natural mortality of fish (Kjesbu et al. 1991, Lambert \& Dutil 2000, Lloret et al. 2013), we hypothesize that deep areas off north-eastern Greenland may contribute significantly to the productivity of the Greenland cod stock and may therefore be potential 'essential fish habitats' (Benaka 1999). Deep rocky bottoms, as are often found in eastern Greenland, are known to 
represent a high-quality habitat for other species such as rockfish Sebastes spp. (Yoklavich et al. 2000) and therefore should deserve particular management measures for protection, including the establishment of marine protected areas (Rosenberg et al. 2000). It must be noted that the physical health of exploited stocks is an essential element of sustainable and profitable fisheries (Lloret et al. 2012, Casini et al. 2016a), and therefore, the results of this study can be of importance for an ecosystem-based approach of fisheries management in Greenlandic waters. In the face of climate change and fishing impacts, ecosystems are expected to alter dramatically, which will impact energy content and the distribution of forage species of cod in Greenland and thereby change habitat suitability (Hansen 1949, Pedersen \& Rice 2002, McBride et al. 2014). Because of the lack of a correlation between habitat quality and density, it appears that cod populations were not able to adapt to habitat changes and persistently inhabited areas with suboptimal food availability. To conclude, our study results support the idea that particular areas in Greenland should receive increased attention and protection in natural resource management because these areas might disproportionally contribute to population stability by sustaining high-conditioned fish, which, once removed, might not be replenished immediately.

Acknowledgements. A. Fernø, F. C. Mark and N. Probst are thanked for their constructive criticism and valuable input, and M. Greenacre and I. Núñez-Riboni are thanked for statistical advice. I. Stoltenberg, C. Schendel, J. Chladek and S. Kochalski are thanked for their support in the lab and I. Wilhelms and J. Appel for technical support. Two anonymous reviewers are thanked for their constructive comments. K.M.W. received financial support from the CLIMA project, reference RER 15/0008, Ministry of Foreign Affairs Norway. The authors have no conflict of interests. Fig. 2 silhouette credits: Benthic fish: Birgit Lang, CC-BY-3.0; Benthic remains: Noah Schlottman, photo from Casey Dunn, CC-BYSA-3.0; Capelin: Tony Ayling (vectorized by T. Michael Keesey), CC-BY-SA-3.0; Crustacea others: Almandine (vectorized by T. Michael Keesey), CC-BY-SA-3.0; Euphausiids: Steven Haddock, Public Domain Mark 1.0; Fish others: M. Kolmann, Public Domain Dedication 1.0; Gadoids: Milton Tan, Public Domain Dedication 1.0; Gammarids: Hans Hillewaert, CC-BY-SA-3.0; Hyperiids: Jason R Eckberg, CC-BYNC-SA-3.0; Mesopelagic fish: Emma Kissling, Public Domain Mark 1.0; Other remains: Becky Barnes, Public Domain Dedication 1.0; Pandalus sp: Maija Karala, CC-BYNC-SA-3.0; Redfish: uncredited, Public Domain Mark 1.0; Sandeel: uncredited, Public Domain Mark 1.0

\section{LITERATURE CITED}

Abrahams MV (1986) Patch choice under perceptual constraints: a cause for departures from an ideal free distribution. Behav Ecol Sociobiol 19:409-415
Aho K, Derryberry D, Peterson T (2014) Model selection for ecologists: the worldviews of AIC and BIC. Ecology 95: 631-636

Akaike H (1974) A new look at the statistical model identification. IEEE Trans Automat Contr 19:716-723

Anderson MJ (2001) A new method for non-parametric multivariate analysis of variance. Austral Ecol 26:32-46

Atkinson E, Wacasey L (1976) Caloric values of zoobenthos and phytobenthos from the Canadian Arctic. Fish Mar Serv Tech Rep 632:1-24

Bartoń K (2012) MuMIn: multi-model inference: https://CRAN. R-project.org/package=MuMIn.

Benaka LR (1999) Summary of panel discussions and steps toward an agenda for habitat policy and science. In: Benaka LR (ed) Proceedings of the sea grant symposium on fish habitat: essential fish habitat and rehabilitation. American Fisheries Society, Bethesda, MD, p 455-459

Bogucki M, Trzesinski P (1950) Fluctuations in the water and fat content of the cod. ICES J Mar Sci 16:208-210

* Bonanomi S, Therkildsen NO, Hedeholm RB, Wæver Pedersen $\mathrm{M}$ and others (2016) Historical DNA documents longdistance natal homing in marine fish. Mol Ecol 25: 2727-2734

Bradbury IRR, Laurel BJJ, Robichaud D, Rose GAA and others (2008) Discrete spatial dynamics in a marine broadcast spawner: re-evaluating scales of connectivity and habitat associations in Atlantic cod (Gadus morhua L.) in coastal Newfoundland. Fish Res 91:299-309

Campana SE (2004) Photographic atlas of fish otoliths of the Northwest Atlantic Ocean. NRC Research Press, Ottawa

Casini M, Eero M, Carlshamre S, Lo J (2016a) Using alternative biological information in stock assessment: condition-corrected natural mortality of Eastern Baltic cod. ICES J Mar Sci 73:2625-2631

* Casini M, Käll F, Hansson M, Plikshs M and others (2016b) Hypoxic areas, density-dependence and food limitation drive the body condition of a heavily exploited marine fish predator. R Soc Open Sci 3:160416

Crawley MJ (2005) Statistics: an introduction using R. John Wiley \& Sons, Chichester

* Cressman R, Křivan V (2010) The ideal free distribution as an evolutionarily stable state in density-dependent population games. Oikos 119:1231-1242

Daan N (1973) A quantitative analysis of the food intake of North Sea cod, Gadus Morhua. Neth J Sea Res 6:479-517

dos Santos J, Jobling M (1991) Factors affecting gastric evacuation in cod, Gadus morhua L., fed single meals of natural prey. J Fish Biol 38:697-713

Drinkwater KF (2005) The response of Atlantic cod (Gadus morhua) to future climate change. ICES J Mar Sci 62: 1327-1337

FFahrig L, Lilly GR, Miller DS (1993) Predator stomachs as sampling tools for prey distribution: Atlantic cod (Gadus morhua) and capelin (Mallotus villosus). Can J Fish Aquat Sci 50:1541-1547

Falk-Petersen IB, Falk-Petersen S, Sargent JR (1986) Nature, origin and possible roles of lipid deposits in Maurolicus muelleri (Gmelin) and Benthosema glaciale (Reinhart) from Ullsfjorden, northern Norway. Polar Biol 5:235-240

Falk-Petersen S, Hagen W, Kattner G, Clarke A, Sargent J (2000) Lipids, trophic relationships, and biodiversity in Arctic and Antarctic krill. Can J Fish Aquat Sci 57: 178-191

*Fossheim M, Primicerio R, Johannesen E, Ingvaldsen RB, Aschan MM, Dolgov AV (2015) Recent warming leads to 
a rapid borealization of fish communities in the Arctic. Nat Clim Chang 5:673-677

Fretwell SD, Lucas HL (1969) On territorial behavior and other factors influencing habitat distribution in birds. I. Theoretical development. Acta Biotheor 19:16-36

Genin A, Dower JF (2007) Seamount plankton dynamics. In: Pitcher TJ, Morato T, Hart PJB, Clark MR, Haggan N, Santos RS (eds) Seamounts: ecology, fisheries \& conservation. Blackwell Publishing, Oxford, p 85-100

Greenacre M, Primicerio R (2013) Multivariate analysis of ecological data. BBVA Foundation, Bilbao

Hansen PM (1949) Studies on the biology of the cod in Greenland waters. Rapp P-V Reùn Cons Int Explor Mer 123:1-85

Härkönen T (1986) Guide to the otoliths of the bony fishes of the Northeast Atlantic. Danbiu Biological Consultants, Hellerup

Henderson RJ, Sargent JR, Hopkins CCE (1984) Changes in the content and fatty acid composition of lipid in an isolated population of the capelin Mallotus villosus during sexual maturation and spawning. Mar Biol 78:255-263

Hovgård H, Wieland K (2008) Fishery and environmental aspects relevant for the emergence and decline of Atlantic cod (Gadus morhua) in West Greenland waters. In: Kruse GH, Drinkwater KF, Ianelli JN, Link JS, Stram DL, Wespestad V, Woodby D (eds) Resiliency of gadid stocks to fishing and climate change. Alaska Sea Grant College Programme, Fairbanks, AK, p 89-110

Kacelnik A, Krebs JR, Bernstein C (1992) The ideal free distribution and predator-prey populations. Trends Ecol Evol 7:50-55

Kennedy M, Gray RD (1993) Can ecological theory predict the distribution of foraging animals? A critical analysis of experiments on the ideal free distribution. Oikos 68:158-166

Kjesbu O, Klungsøyr J, Kryvi H, Witthames PW, Walker MG (1991) Fecundity, atresia and egg size of captive Atlantic Cod (Gadus morhua) in relation to proximate body composition. Can J Fish Aquat Sci 48:2333-2343

Kurlansky M (2011) Cod: a biography of the fish that changed the world. Penguin Group, New York, NY

* Lambert Y, Dutil JD (1997) Can simple condition indices be used to monitor and quantify seasonal changes in the energy reserves of cod (Gadus morhua)? Can J Fish Aquat Sci 54:104-112

* Lambert Y, Dutil JD (2000) Energetic consequences of reproduction in Atlantic cod (Gadus morhua) in relation to spawning level of somatic energy reserves. Can J Fish Aquat Sci 57:815-825

Lea MA, Nichols PD, Wilson G (2002) Fatty acid composition of lipid-rich myctophids and mackerel icefish (Champsocephalus gunnari) - Southern Ocean food-web implications. Polar Biol 25:843-854

Lee RF, Hagen W, Kattner G (2006) Lipid storage in marine zooplankton. Mar Ecol Prog Ser 307:273-306

Lie $\varnothing$, Lied E, Lambertsen G (1988) Feed optimization in Atlantic cod (Gadus morhua): fat versus protein content in the feed. Aquaculture 69:333-341

Lilly GR, Parsons DG (1991) Distributional patterns of the northern shrimp (Pandalus borealis) in the northwest Atlantic as inferred from stomach contents of cod (Gadus morhua). ICES C.M. 1991/K:41, p 265-275

Link JS, Garrison LP (2002) Trophic ecology of Atlantic cod Gadus morhua on the northeast US continental shelf. Mar Ecol Prog Ser 227:109-123

Lloret J, Rätz HJ (2000) Condition of cod (Gadus morhua) off Greenland during 1982-1998. Fish Res 48:79-86
Lloret J, Faliex E, Shulman GE, Raga JA and others (2012) Fish health and fisheries, implications for stock assessment and management: the Mediterranean example. Rev Fish Sci 20:165-180

Lloret J, Shulman G, Love RM (2013) Condition and health indicators of exploited marine fishes. John Wiley \& Sons, Chichester

* Marshall CT, Yaragina NA, Lambert Y, Kjesbu OS (1999) Total lipid energy as a proxy for total egg production by fish stocks. Nature 402:288-290

Marteinsdottir G, Steinarsson A (1998) Maternal influence on the size and viability of Iceland cod. J Fish Biol 52: 1241-1258

McBride MM, Dalpadado P, Drinkwater KF, Godø OR and others (2014) Krill, climate, and contrasting future scenarios for Arctic and Antarctic fisheries. ICES J Mar Sci 71:1934-1955

Mcbride RS, Somarakis S, Fitzhugh GR, Albert A and others (2015) Energy acquisition and allocation to egg production in relation to fish reproductive strategies. Fish Fish 16:23-57

* Morais S, Bell JG, Robertson DA, Roy WJ, Morris PC (2001) Protein/lipid ratios in extruded diets for Atlantic cod (Gadus morhua L.): effects on growth, feed utilisation, muscle composition and liver histology. Aquaculture 203: 101-119

* Morris DW (2011) Adaptation and habitat selection in the eco-evolutionary process. Proc Biol Sci 278:2401-2411

Munday PL (2001) Fitness consequences of habitat use and competition among coral-dwelling fishes. Oecologia 128: 585-593

Neat FC, Wright PJ, Zuur AF, Gibb IM and others (2006) Residency and depth movements of a coastal group of Atlantic cod (Gadus morhua L.). Mar Biol 148:643-654

*Norrbin F, Båmstedt U (1984) Energy contents in benthic and planktonic invertebrates of Kosterfjorden, Sweden. A comparison of energetic strategies in marine organism groups. Ophelia 23:47-64

Oksanen J, Blanchet FG, Friendly M, Kindt R and others (2018) Vegan: community ecology package. R package version 2.5-2. https://CRAN.R-project.org/package=vegan

* Pardoe H, Thórdarson G, Marteinsdóttir G (2008) Spatial and temporal trends in condition of Atlantic cod Gadus morhua on the Icelandic shelf. Mar Ecol Prog Ser 362: 261-277

*Parker GA, Sutherland WJ (1986) Ideal free distributions when individuals differ in competitive ability: phenotype-limited ideal free models. Anim Behav 34: 1222-1242

Pedersen SA, Rice JC (2002) Dynamics of fish larvae, zooplankton, and hydrographical characteristics in the West Greenland large marine ecosystem 1950-1984. In: Sherman K, Skjoldal HR (eds) Large marine ecosystems of the North Atlantic: changing states and sustainability, 1st edn. Elsevier Science, Amsterdam, p 151-194

R Development Core Team (2016) R: a language and environment for statistical computing. R Foundation for Statistical Computing, Vienna. www.r-project.org

Rätz HJ, Lloret J (2003) Variation in fish condition between Atlantic cod (Gadus morhua) stocks, the effect on their productivity and management implications. Fish Res 60: 369-380

* Røjbek MC, Jacobsen C, Tomkiewicz J, Støttrup JG (2012) Linking lipid dynamics with the reproductive cycle in Baltic cod Gadus morhua. Mar Ecol Prog Ser 471:215-234 
Rosenberg A, Bigford TE, Leathery S, Hill RL, Bickers K (2000) Ecosystem approaches to fishery management through essential fish habitat. Bull Mar Sci 66:535-542

Schwarz G (1978) Estimating the dimension of a model. Ann Stat 6:461-464

Scott WB, Scott MG (1988) Atlantic fishes of Canada. Canadian Bulletin of Fisheries and Aquatic Sciences, No. 219, University of Toronto Press, Toronto

Smith JM, Slatkin M (1973) The stability of predator-prey systems. Ecology 54:384-391

Spitz J, Mourocq E, Schoen V, Ridoux V (2010) Proximate composition and energy content of forage species from the Bay of Biscay: high- or low-quality food? ICES J Mar Sci 67:909-915

Stamps J (2009) Habitat selection. In: Levin SA (ed) The Princeton guide to ecology. Princeton University Press, Princeton, NJ, p 38-44

Stoltenberg I (2019) Regional influences on condition and reproductive outcome of female Atlantic cod (Gadus morhua) in Greenland waters. MS thesis, GEOMAR, Kiel

Storr-Paulsen M, Wieland K, Hovgård H, Rätz HJ (2004) Stock structure of Atlantic cod (Gadus morhua) in West Greenland waters: implications of transport and migration. ICES J Mar Sci 61:972-982

Sutherland WJ (1996) From individual behaviour to population ecology. Oxford University Press, Oxford

Svedäng H, Righton D, Jonsson P (2007) Migratory behaviour of Atlantic cod Gadus morhua: natal homing is the prime stock-separating mechanism. Mar Ecol Prog Ser 345:1-12

Editorial responsibility: Stylianos Somarakis, Heraklion, Greece
Tregenza T (1995) Building on the ideal fee distribution. Adv Ecol Res 26:253-307

Tyler AV (1973) Caloric values of some North Atlantic invertebrates. Mar Biol 19:258-261

Whitehead PJP, Bauchot ML, Hureau JC, Nielsen J, Tortonese E (1984) Fishes of the North-eastern Atlantic and the Mediterranean. UNESCO, Paris

Whitfield AK, Blaber SJM (1978) Food and feeding ecology of piscivorous fishes at Lake St Lucia, Zululand. J Fish Biol 13:675-691

Wickham H (2016) Ggplot2: elegant graphics for data analysis. Springer-Verlag, New York, NY

*Wood SN (2011) Fast stable restricted maximum likelihood and marginal likelihood estimation of semiparametric generalized linear models. J R Stat Soc 73:3-36

Y Yaragina NA, Marshall CT (2000) Trophic influences on interannual and seasonal variation in the liver condition index of Northeast Arctic cod (Gadus morhua). ICES J Mar Sci 57:42-55

Yoklavich MM, Greene HG, Cailliet GM, Sullivan DE, Lea RN, Love MS (2000) Habitat associations of deep-water rockfishes in a submarine canyon: an example of a natural refuge. Fish Bull 98:625-641

*Yoneda M, Wright PJ (2005a) Effect of temperature and food availability on reproductive investment of first-time spawning male Atlantic cod, Gadus morhua. ICES J Mar Sci 62:1387-1393

Yoneda M, Wright PJ (2005b) Effects of varying temperature and food availability on growth and reproduction in firsttime spawning female Atlantic cod. J Fish Biol 67: 1225-1241

Submitted: June 26, 2019; Accepted: August 27, 2019 Proofs received from author(s): October 10, 2019 